\title{
A Field Test of the Cougar Home Safety Assessment for Older Persons Version 1.0
}

\author{
Grace S. Fisher, Kristen Coolbaugh, \& Christin Rhodes \\ College Misericordia
}

\begin{abstract}
After reviewing the literature on environmental safety and existing home safety evaluation tools, the researchers developed the Cougar Home Safety Assessment Version 1.0 (Cougar 1.0). This assessment is a 56-item tool for identifying environmental safety hazards in the homes of older persons. The first purpose of this study was to develop and field test the Cougar 1.0 to determine its inter-rater reliability and validity. The second purpose was to identify specific environmental safety hazards in the residences of older persons during the field test. Three graduate occupational therapy students administered the Cougar 1.0 in the homes of 14 older persons within one county of northeastern Pennsylvania. The instrument was found to have a moderate level of inter-rater reliability, as Cohen's Kappa for the ratings of the 3 raters was .506. Percent agreement between the three raters was 90 percent. The field test found that the most frequently unsafe aspects of the homes were: a lack of grab bars near toilets; no emergency numbers posted near phones; the presence of non-grip throw rugs; lack of fire extinguishers; and lack of step stools. Participating residents and occupational therapy home safety specialists provided positive feedback regarding the content validity of the Cougar 1.0. This research suggests that the use of this instrument by occupational therapists may prevent client injuries in the home.
\end{abstract}

(c) 2006 Californian Journal of Health Promotion. All rights reserved.

Keywords: home safety, environment, assessment

This instrument development report describes the findings of a field test on the Cougar Home Safety Assessment for Older Persons, Version 1.0 (Cougar 1.0). There were two purposes of our study. The first purpose was to develop and field test the Cougar 1.0 to determine its interrater reliability and content validity. The second purpose was to identify specific environmental safety hazards in the residences of older persons during the field test. It was hoped that the development of a reliable environmental safety assessment and information on the types of existing safety hazards would help occupational therapy practitioners meet the environmental safety needs of older persons living independently in the community.

Depoy and Gitlin (2005) suggest the following steps in instrument development: (a) conduct literature review, (b) establish theory base, (c) determine concept to be measured, (d) design framework, (e) identify content and criteria, (f) test usefulness. With these steps in mind, we began this investigation with a literature review. Later parts of this report will address how we followed the subsequent steps when we developed the Cougar 1.0.

\section{Older People and Their Residences}

The issue of environmental safety has become increasingly important, due to the everincreasing number of elderly living in this country. The U.S. Census Bureau (2001) defines an elderly person as one who is 65 years of age or older. According to the U.S. Census Bureau's 2000 survey, there are over 35 million elderly persons in the United States.

In 2003, approximately $30 \%$, or 10.5 million, of all non-institutionalized older persons lived alone (U. S. Department of Health and Human Services, 2003). The same source reported that another $53.6 \%$ of non-institutionalized older persons lived with their spouses. At the time of 
the report, approximately $5 \%$ of the population of older persons lived in various types of senior housing, where they were provided with support services as needed. This $5 \%$ did not include older persons in nursing homes.

\section{People}

Falls and Other Accidents in Older

The National Center for Injury Prevention and Control (n.d., a, b, c, d, and e) provides important statistics related to accidents in the home. The Center reported that unintentional injuries accounted for the deaths of approximately 66,000 Americans over the age of 65 in 2002. Of the 66,000 deaths, approximately 12,000 deaths occurred secondary to falls and approximately 2,000 deaths occurred secondary to residential fires or burns. Over 1.8 million Americans injured themselves falling in 2003. The center also reported that falls were the leading cause of unintentional injuries for the population of older persons 65 and older.

More than \$20.2 billion dollars in medical costs is spent each year on treating injuries secondary to falls among older persons, and by the year 2020 , this amount is expected to reach \$32.4 billion (Fleming, 2002). Unintentional burn injuries totaled 22,000 in the year 2003 for those 65 years of age and older (National Center for Injury Prevention and Control, n.d., d). In 1999, Medicare spent more than eight billion dollars on treatment of burns, nerve damage, poisonings, dislocations, open wounds, and other injuries (Brandeis University, 2003).

According to Woodland and Hobson (2003), falls can be attributed to two types of factorsintrinsic and extrinsic. Intrinsic factors include a history of falling, risk-taking behaviors, reduced hearing, and medication side effects. Extrinsic factors include throw rugs, a lack of safety equipment in the bathroom, slippery surfaces, and temporary obstructions in walkways. Woodland and Hobson contend that consideration of both the intrinsic and extrinsic factors is important in determining a person's fall risk. They state that occupational therapists should be aware of both types of factors. Because the unique focus of occupational therapy considers occupation as well as the person and environment, occupational therapists can enhance the knowledge base associated with fall prevention.

\section{Safety in the Home Environment}

A number of studies have examined the importance of the environment in assuring home safety. Gill, William, Robison, and Tinetti (1999) conducted an investigation to determine the prevalence of environmental hazards in different types of housing for persons with varying ADL (activities of daily living) abilities. The two housing types studied were agerestricted housing and community housing. The study found at least two hazards in 59\% of bathrooms and in up to $42 \%$ of the other rooms of the households screened.

Clemson, Roland, and Cumming (1997) used an abbreviated version of the Westmead Home Safety Assessment to find the most common hazards in the dwellings of older persons. The study determined that $48 \%$ of hazards found were in internal traffic ways; $40 \%$ were in bathrooms; and 38\% were in "to/from" home access areas. The most common individual hazards found were hazardous mats, pathways, and bathroom floor surfaces.

A study by Tanner (2003) assessed safety in the homes of older adults aged 60 years and up. Nursing students visited the participants' homes twice per week for one hour over a period of four weeks. The Home Safety Assessment Tool was used. Subscales that were used included: (a) risk for falls: external factors, (b) risk for falls: internal factors, (c) history of falls, (d) risk for injury: use of personal precautions, (e) risk and preparation for fire and disasters, and (f) risk for crime. The study found that the subscale at highest risk was external risk factors, with $44 \%$ of the participants scoring at moderate or highrisk levels. Over $41 \%$ of the participants reported that they did not have grab bars, resulting in the potential for a great number of falls (Tanner, 2003).

Eugene Cannava (1994, p. 45) described the need for an "aging-friendly" environment; this type of environment aids in the functional independence of older persons. Flooring, 
seating, tables, light, color, and safety issues are the main areas of concern in what he called "Gerodesign.” “Gerodesign” is a term used to describe an environment that is user-friendly for older adults. Cannava noted ways of fixing problem areas include adjusting work areas to the appropriate height, selecting handles that do not require excessive twisting motions, installing grab bars, providing nonskid surfaces, and preparing the environment for evacuation in the case of an emergency. He contended that an environment that is safe and pleasing to the eye can help older persons function at optimal levels.

\section{Home Safety: International Concerns}

Safety in the homes of older persons is not only a problem in the United States; it is an international concern. The Department of Health in New South Wales, Australia, noted an increasing need for preventative home safety programs (Close, Ellis, Hooper, Glucksman, \& Jackson et al., 1999).

A study was conducted in Umea, Sweden to investigate whether a multifactorial intervention program would reduce falls and fall-related injuries in the elderly. The participants included 439 persons who were 65 years of age or older living in nine residential care facilities (Jensen, Lundin-Olsson, Nber, \& Gustafson, 2002). Each facility was assessed for environmental hazards such as flooring, obstacles, lighting, and dangerous areas outside the facility. Exercises, assistive devices, assistive aid repairs, medication changes, hip protectors, and post-fall problem-solving conferences were among the intervention methods used. During the follow-up period, nurses' aids reported each fall they witnessed or that was reported to them. The study found that $44 \%$ of the residents in the intervention group fell, while 56\% in the control group fell. This suggested that the multi-factorial intervention program may have slightly reduced the number of residents who fell.

A study conducted in Australia was designed to determine the association between sociodemographic characteristics and the amount of safety hazards in homes of persons 70 years and older (Carter, Campbell, Sanson-Fisher,
Redman, \& Gillespie, 1997). By implementing safety house-checks and conducting interviews, the investigators found that $39 \%$ of the homes had more than five hazards; $87 \%$ identified at least one hazard; and $30 \%$ of the people who said that their home was safe had more than five environmental safety hazards. A logistic regression analysis showed that contact with a healthcare service provider was associated with a smaller number of hazards. Homes that had never been visited by a healthcare provider were twice as likely to have more than five hazards.

\section{Occupational Therapy Home Safety Interventions}

The occupational therapy profession plays a vital role the area of home safety. A study in 2000 conducted by Salkeld, Glen, Cumming, O’Neill, Thomas, Szonyi, and Westbury focused on reducing the number of falls among older persons (AARP, 2002). The intervention group in the study received a home assessment by an occupational therapist as well as any necessary home modifications. The study resulted in the intervention group having a fall rate of 1.25 falls per person per year as opposed to 2.24 per person per year in the control group.

Close et al. (1999) provided evidence for the usefulness of medicine and occupational therapy in decreasing falls in older adults. Occupational therapy involvement in the study involved education, advice, modifications, and equipment to assist with home safety. Another study that confirmed the important of occupational therapy in assuring home safety was conducted by Wilkins, Jung, Wishart, Edwards, and Norton (2003). That investigation showed that an occupational therapy evaluation of a home reduced the risk of falls within the home and surrounding areas of older persons who have a history of falls.

A recent occupational therapy study looked for disparities in home evaluation recommendations for inner city clients with different types of health insurance (Lysack \& Neufeld, 2003). General results of the study showed that recommendations for adaptive equipment were slightly more common than home modification recommendations. It was found that patients 
with public health insurance received fewer home modification recommendations than those with private health insurance.

An occupational therapy study in 2001 involved revisiting participants in a 1997 investigation to see if they were adhering to environmental modification recommendations made in the earlier investigation (Cumming et al., 2001). Twenty-five (21\%) of the participants did not adhere to any recommendations and 26 (21\%) fully or partially adhered to all recommendations. Participants who believed it was possible to prevent falls by making home modifications were more than twice as likely to adhere than those who did not believe it was possible. Sixty-five percent of the participants at least partially adhered to 50 percent or more of the recommendations.

Occupational therapists investigated factors associated with elderly urban African-American women who return to living alone after their discharge from rehabilitation programs (Lysack, MacNeill, \& Lichtenberg, 2001). The researchers found that nearly half $(43 \%)$ of elderly urban African-American women who lived alone before admission returned immediately to live alone status following discharge. The rate of return to live-alone status increased to $65 \%$ six months after discharge. These high percentages demonstrated the need for the development of measures of environmental safety for the residences of older people living alone who may be at risk for falls or other accidents.

Suffering due to disability and deaths is emotionally taxing as well as costly (Miller, 2003). Miller emphasized that the occupational therapy profession must play a key role in educating others about safety concerns within the home and community. By doing so, the occupational therapy profession can demonstrate its important role in this area. According to Miller, older persons and their families in need of identifying and eliminating safety hazards in the home and community can benefit from this information. By eliminating home safety hazards, older people may be able to live independently for longer periods of time.
Moving to an assisted living facility may not be necessary if more programs to promote safety in the home are developed.

Russell, Fitzgerald, Williamson, Manor, and Whybrow (2002) described the safety clause as the belief in patients and/or caregivers being autonomous decision makers - as long as the therapist deems it safe. These researchers described the ethical conflict which emerges when there is a disparity between what the therapist recommends and what the client wishes to do. Occupational therapists may experience conflict between the legal rights of clients to do what they want to do versus the therapists' professional duty to provide healthcare or make recommendations.

\section{Occupational Therapy Fall Prevention Assessments}

A recent occupational therapy study involved the development of an assessment to evaluate behavioral factors that protect people from falling (Clemson, Cumming, \& Heard, 2003). The investigators developed an instrument called the Falls Behavioral Scale for Older People. Ten "dimensions" were isolated that contributed to understanding the behaviors and actions associated with the adaptations that older persons make to enhance their safety and protect themselves from falling. These include using a handrail, looking ahead for potential hazards when walking outdoors, avoiding ramps and other slopes, using a light when getting up at night, keeping shrubbery and plants trimmed back from pathways outdoors, noticing spills on the floor, and talking with someone about ways to prevent falls.

Another recent occupational therapy study investigated the validity of the Falls Efficacy Scale (FES), The Survey of Activities and the Fear of Falling in the Elderly (SAFE), and the Activities-Specific Balance Confidence Scale (ABC) (Hotchkiss, Fisher, Robertson, Ruttencutter, Schuffert et al., 2004). The study determined that none of the three assessments were able to accurately predict a person's frequency of falls, frequency of leaving the home, or the level of activity restriction. This indicated the need for the development of new 
assessments that can help improve home safety and in turn reduce the likelihood of falling.

\section{Assessments \\ Environmental Home Safety Effective home safety intervention begins with assessment. The Person-Environment-} Occupation (PEO) model of practice stresses the importance of all three PEO domains, and serves as the theoretical basis for a number of occupational therapy assessments (Letts, Baum, \& Perlmutter, 2003). However, because some of these assessments place much emphasis on the person and his/her occupational performance, they can not look in a very detailed way at specific environmental safety hazards. For example, Letts et al. note that the Functional Impairment Profile, the Memory and Behavior Problems Checklist, the Functional Behavior Profile, and the Revised Kitchen Task Assessment are PEO-based assessments which emphasize the person. They also point out that the Activity Card Sort and the Reintegration to Normal Living Index are assessment tools which emphasize occupation. There are not many occupational therapy assessments available which address features of the home from the standpoint of environmental safety in an indepth way.

Thorough environmental assessments are needed to prevent injuries and to deal with underlying architectural barriers and unsafe practices (Klein \& Ritzel, 2001). Some existing home assessments have been designed to evaluate the level of safety within residences. The Safety for Older Consumers Home Safety Checklist, which was developed by the Consumer Product Safety Commission (n.d.), instructs the evaluator to assess areas of the home, including electrical and telephone cords, rugs, runners and mats, telephone areas, smoke detectors, electrical outlets and switches, light bulbs, space heaters, wood burning stoves, and emergency exit plans.

The Safety Assessment of Function and the Environment for Rehabilitation (SAFER) tool was developed by occupational therapists for occupational therapists in order to evaluate the ability of seniors and disabled persons to maintain their independence and live safely in their homes and in the community (Comprehensive Rehabilitation and Mental Health Services, 2003). Both the SAFER and another standardized tool called The Home Occupational Environment Assessment provide useful occupational therapy strategies for assessing a client's residence (Letts et al., 2003).

We acknowledge the existence of these and other excellent assessments. However, our review showed that there was a need for an indepth occupational therapy assessment which more closely examines the many important aspects of environmental safety. We propose that this is an emerging occupational therapy practice area with much potential for development. Therefore, we decided to develop a user-friendly tool that exclusively addressed the environment and did not address client ability. The tool we developed is The Cougar Home Safety Assessment for Older Persons Version 1.0. (Cougar 1.0).

\section{Method}

Institutional Review Board approval for this study was obtained at our college. Once approval was obtained, our study commenced.

\section{Instrumentation: The Cougar 1.0}

Choosing an environmental assessment instrument was the first step involved in our study. Prior to developing the Cougar 1.0, we first explored the possible use of existing environmental assessments. The most comprehensive one which we found was the Safety for Older Consumers Home Safety Checklist. Although we found the checklist to be very helpful, we thought it was too detailed for our purpose. We also determined that it was too time consuming for an occupational therapist to administer within the course of one home visit. We sought to develop an environmental assessment tool for the home which would yield important information and at the same time could be administered in approximately one hour. After a thorough review of existing assessments, we decided to develop our own tool by adapting the Safety for Older Consumers Home Safety Checklist. The Safety for Older Consumers Home Safety Checklist is a publicdomain document found on the Internet. The 
Consumer Product Safety Commission generously grants permission to interested parties to utilize the Safety for Older Consumers Home Safety Checklist without permission. The Commission requests that they simply be notified when their checklist is reproduced or used in part. We have provided them with detailed information in this regard, according to their guidelines.

We, the researchers, adapted the Safety for Older Consumers Home Safety Checklist by condensing and paraphrasing its elements, and by selecting those criteria which we felt were within the scope of occupational therapy practice. We examined each criterion on an item by item basis to determine if it should be included on our instrument. We paraphrased and rephrased each chosen criteria to reflect the Cougar 1.0's unique format. A distinct effort was made to state each criterion in a clear and very concise manner. We devised a simple rating scale for the assessment criteria. The faculty chairperson and three graduate student researchers participated in this document adaptation process by continually examining, discussing, and refining the Cougar $1.0 \mathrm{draft}$ during a series of approximately 8 weekly one hour meetings. Thus we developed the Cougar 1.0 .

The Cougar 1.0 consists of 56 safety criteria. Each safety criterion is rated safe, unsafe, or not applicable. There is also an area for rater comments related to each criterion. The Cougar 1.0 is available online (Coolbaugh, Rhodes, \& Bryan, 2004).

\section{Pilot Test}

Three occupational therapy graduate student researchers first piloted the use of the Cougar 1.0, with their research committee faculty chairperson, at the home of one of the researchers- to refine the assessment tool. Procedures for administration of the assessment were developed and followed by all researchers. The faculty advisor observed the student researchers in their administration of the assessment, and deemed them competent in its usage. It was determined that the time frame for administration of the Cougar 1.0 would be approximately one hour.

\section{Participating Residents}

In order to recruit participating residents, one researcher attended a meeting at a local church and held an informal information seminar to explain the purpose, methods, and criteria for participation in the study, and to allow any interested persons to ask questions. Inclusion criteria for the study involved being 65 years of age or older and living within the community in a home or apartment. A sign up sheet was made available for those who were interested in participating. Four residents signed up at the meeting. Word of mouth referrals of some potential resident participants were also obtained from a family member of the student researcher who was also a member of that church. That student researcher then contacted potential resident participants by telephone to determine their willingness to be in the study. If the individual agreed to participate, an appointment was made for the researchers to visit the resident's home to conduct the assessment.

\section{Procedure}

DePoy and Gitlin (2005) state that new instruments need to be tested for validity and reliability. They suggest testing for reliability and content validity, in particular. Bailey (1997) notes three aspects of reliability that are important in instrument development: testretest, split-half, and inter-rater. We chose to focus this, our initial investigation of the Cougar 1.0 , on inter-rater reliability. We felt that the other aspects of reliability could be addressed in later studies.

Establish Inter-Rater Reliability. Inter-rater reliability is the degree to which separate raters agree when grading criteria or making observations of the same phenomenon during testing. We conducted a field test of the Cougar 1.0 assessment in order to establish its inter-rater reliability. After our pilot assessment was completed, three occupational therapy graduate student investigators simultaneously visited 14 residences of older persons age 65 and older. All of these older persons lived independently in 
their own private homes or apartments in the community.

After obtaining informed consent from each participating resident, the assessment process began. Participating residents were asked to complete a demographic information sheet. Demographic information collected included age, gender, type of housing, assistance received, and accidents that happened.

In the next step, the three graduate student researchers assessed each residence simultaneously (using the Cougar 1.0), asking questions and seeking clarification from the residents. The three raters then separately and privately made their own individual ratings on all the criteria of the Cougar 1.0. At the time of the assessment the raters did not converse with each other about their ratings, nor did they view each others' findings.

Establish Content Validity- Participating Resident and OT Specialist Expert Panels. The content validity of an instrument is the extent to which its criteria represent the construct being measured (DePoy \& Gitlin, 2005). Portney and Watkins (2000) state that content validity is established subjectively. They suggest having an expert panel review the instrument to determine if its criteria adequately address what they seek to measure. Therefore, we established two expert panels to address the content validity of the Cougar 1.0: a panel of O.T. specialists, and the panel of participating residents.

After the three raters completed their assessments of each home, the participating residents were asked to complete a questionnaire in which they gave their opinion of the assessment process. The researchers also sent a survey to O.T. specialists to obtain their opinion on the validity of the Cougar 1.0. The O.T. specialist surveys were sent to occupational therapy practitioners listed in the American Occupational Therapy Association (AOTA) specialist directory under the categories of accessibility/ adaptive devices, advocacy/ independent living, environment, home care, and geriatrics (AOTA, n.d.). Email requests were sent to 126 OT specialists. In these requests, the O.T. specialists were asked to examine the Cougar 1.0 and answer six questions which focused on the content and structure of the assessment.

\section{Data Analysis}

Inter-Rater Reliability. The most commonly used indices for inter-rater reliability include percent agreement, Cohen's kappa, Holsti's method, Scott's pi, and Krippendorff's alpha (Stemler, 2001). If calculating percent agreement to examine inter-rater reliability, Stemler recommended that Cohen's kappa also be determined. This is because the calculation of percent agreement does not account for the likelihood that by chance alone raters may have rated something identically. Cohen's kappa does account for the fact that chance identical ratings may have occurred. Therefore, we calculated percent agreement and Cohen's kappa for the findings of the three researchers on the 14 Cougar 1.0 assessments. We used the Program for Reliability Assessment with Multiple Coders (PRAM) to perform these calculations (Skymeg Software, n.d.). PRAM is recommended as an effective software program for calculating interrater reliability statistical measures (Lombard, Snyder-Duch, \& Backen, 2004).

Most Common Ratings on Cougar 1.0. After the aforementioned calculation of inter-rater reliability, the Cougar 1.0 ratings of the three raters were then analyzed to determine the most common rating across all three raters. For example, if one rater identified a criterion as safe and two raters identified the same criterion as unsafe, the most common rating was determined as unsafe. Frequency counts and percentages of the number of safe, unsafe, and not applicable findings were tabulated using both SPSS 11.0 (Statistical Package for Social Sciences, n.d.) and Excel software (Microsoft Office Online, n.d.).

Participating Resident and OT Specialist Questionnaires. Descriptive statistics, using Microsoft Excel and SPSS 11.0, were calculated on the quantitative data obtained via the participating resident and OT specialist questionnaires. A content analysis was 
conducted to analyze the written comments of the participating residents and the OT specialists.

\section{Results}

\section{Participating Residents}

The Cougar 1.0 pilot study included 14 participating residents (13 females and one male), with an average age of 77 years. Seven participating residents lived in two story homes; three participating residents lived in ranch style homes; two participating residents lived in apartments; and two participating residents lived in double block homes. The average number of rooms per home was seven. One residence had six rooms; two had eleven rooms; two residences had nine rooms; two residences had seven rooms; three residences had eight rooms; and four residences had five rooms. The participating residents' socioeconomic circumstances were observed by the graduate student researchers to range from low- to highmiddle class, and different ethnic backgrounds were observed.

Out of 14 participating residents, ten stated that they received assistance in their homes. The distance between the participating residents' residences and the residences of those providing assistance ranged from 0 miles (for those living with the participating residents) to 16 to 20 miles away. The average distance between the participants' homes and their respective assistance providers was 4.6 miles.

Two of the fourteen participating residents stated that they fell in their homes within the last year. The remaining twelve participating residents reported no falls or injuries.

\section{Inter-rater Reliability of Cougar 1.0}

The percent agreement of the three raters at the 14 residences was 0.901, indicating 90\% agreement. The Cohen's Kappa calculation for the 3 raters was found to be 0.506 . Stemler (2001) reported that a Cohen's kappa at this level represents moderate strength of agreement between raters.

\section{Cougar 1.0 Findings}

The most common ratings for all 56 Cougar 1.0 criteria are displayed in Appendix A. The items that were found unsafe in the majority of homes include the following: lack of grab bars near toilets, no emergency numbers posted near phones, presence of non-grip throw rugs, lack of fire extinguishers, and lack of step stools. Twenty criteria of the Cougar 1.0 were found to be safe in all participating residents' homes.

\section{Participating Resident Feedback}

All 14 participating residents completed and returned their feedback questionnaires, resulting in a response rate of $100 \%$ on this component of the study. Their responses were: Were Any Areas of Your Home Identified as Unsafe? (86\%); Do you plan to make changes to your home based on the Cougar 1.0? (71\%); Did you learn new information about home safety? (71\%).

As part of the participating resident questionnaire, all 14 participating residents were asked if any areas of their homes were identified as unsafe by the researchers. $86 \%$ of participating residents stated that one or more areas of their home were identified as unsafe. This is critical to the field test because unsafe areas were found in all of the participating residents' homes, even though $14 \%$ of participating residents did not recognize this. This gap appears to indicate a need for a followup visit by an occupational therapist, after residents undergo initial assessment via the Cougar 1.0

As part of the participating resident questionnaire, participants were asked if they planned on making changes to correct the unsafe areas that were identified during the Cougar 1.0 pilot study. $71 \%$ of participating residents stated that they planned on making changes to their homes based on the feedback from the Cougar 1.0 researchers. Additionally, $71 \%$ of the participating residents stated that they learned new information about home safety by participating in the Cougar 1.0 pilot study. 


\section{O.T. Specialist Feedback}

35 of the 126 O.T. specialists to whom we sent e-mails responded by completing the survey, resulting in a response rate of $28 \% .86 \%$ of the O.T. specialists stated that the Cougar 1.0 does address the main environmental safety issues facing older persons in their homes. 91\% of the specialists stated that the Cougar 1.0 was designed in a user-friendly format and $74 \%$ of specialist responders stated that they would use the Cougar 1.0 in practice if it were available in print.

When asked to state the strengths of the Cougar $1.0,37 \%$ stated that it was quick and simple; $37 \%$ stated that it was comprehensive, and five specialists responded that it was organized well.

\section{O.T. Specialist Suggestions for Altering} Cougar 1.0. The O.T. specialists responded to the question of how the Cougar 1.0 should be changed in the following manner: $31 \%$ of the specialists stated that the Cougar 1.0 should not only address the safety of the environment but should take into consideration the physical ability and mental status of the clients. 9\% of the specialists felt that the Cougar 1.0 should be more compact. $11 \%$ questioned the point of adding up the scores: "What is the point of adding up safe/unsafe? What is the value of identifying a numerical score?” One specialist asked, "What is the significance of the score? It seems to me that any one issue could have disastrous implications depending on the situation." The importance of creating an assessment such as the Cougar 1.0 is indirectly reinforced by the previous quote- it addresses the need to decrease or eliminate safety hazards in the homes of older persons.

Regarding the question as to whether or not safety areas should be added to the Cougar 1.0, $37 \%$ of the specialists would add a section regarding clients' abilities instead of just addressing the environment, $11 \%$ agreed that a section for doorways should be added, $11 \%$ had the opinion that medication should be addressed, and $9 \%$ stated that accessibility in regard to entrances and exits of the home should be addressed.

\section{Discussion}

Our findings demonstrate that the Cougar 1.0 possesses moderate inter-rater reliability. Additional studies are needed to investigate the instrument's test-retest and split-half reliability. The content validity of the Cougar 1.0 assessment is supported by the favorable comments of both the O.T. specialists and the participating residents.

\section{Education \\ Recommendations for Practice and} The researchers recommend the use of the Cougar 1.0 by practicing occupational therapists. Occupational therapists in facility-based practice can collaborate with clients in completing the checklist or use the assessment as a guide when they visually inspect residences during home visits. The Cougar 1.0 could also be useful in the home health area of practice to determine specific hazards in need of modification.

Certified occupational therapy assistants may be trained to use the Cougar 1.0. The Cougar 1.0 could be used by other professionals such as physical therapists and nurses as part of a home health care plan. One O.T. specialist stated that the Cougar 1.0 "could be used as a take home list for a family to save treatment time when a therapist is with the individual to determine what works best in their environment for what they typically do in it." The Cougar 1.0 could also be utilized by occupational therapy professionals as a screening tool for environmental safety hazards in community based programs for the well elderly.

A need for placing more emphasis on home safety in O.T. educational programs to prepare future occupational therapists may be indicated. Training occupational therapy students in the use of the Cougar could contribute to their ability to assure the home safety of their clients.

\section{Recommendations for Further Development of the Cougar}

Continued refinement of the Cougar 1.0 is recommended. Fellow student researchers have already very recently refined it through the development of the Cougar 2.0 and 3.0. Reports from these later instrument development studies 
are currently being written and will be disseminated in the future. Continued revisions will help insure the creation of a strongly reliable and valid assessment.

There is also increasing recognition of the potential value of revising the Cougar so that it addresses the person and occupation, in addition to the environment. It is recognized that inclusion of these other factors would render a more comprehensive assessment tool. Nonetheless, the researchers are cautious in this regard. They are concerned that an effort to examine multiple factors- such as client performance- may dilute the assessment's emphasis on the environment.

\section{Limitations}

One limitation of our study was the small sample size of fourteen participating residents. Other limitations include the student researchers' limited time to participate in the study (one college semester for data collection, and one college semester for data analysis and report-writing), a limited geographic area of study, and the fact that the participating residents were predominantly Caucasian females. Another limitation may have been the use of the alpha version of PRAM to analyze our data. This may be detrimental to the results because the PRAM software program is rather new and may still contain problems areas. Future research and development of the Cougar needs to consider these limitations.

\section{Conclusion}

Numerous studies indicate the need for environmental assessment by instruments such as the Cougar 1.0. For example, Klein and Ritzel (2001) reported falls to be responsible for 50\% of all injury-related deaths in older persons, and recommend that health care professionals consider both individual and environmental factors to reduce falls in older persons. Beghe (2004) found that risk of falling in older people was reduced by using a "multidisciplinary, multifactorial, health, or environmental risk factor screening or intervention program” (p. 2). Weir and Culmer (2004) reported that "a directed assessment and modification of environmental hazards” (p. 1) can be a benefit to those with a history of falls.

Safety hazards may exist secondary to a lack of awareness on the part of older persons. According to one of our study's participating residents, assessment via the Cougar 1.0 can increase awareness: "[The Cougar 1.0] demonstrates what areas of a home are potentially dangerous and creates awareness of such circumstances and provides suggestions for remedying such hazards.” Decreased awareness may stem from a lack of resources such as pamphlets and educational training for older persons and/or their caregivers in communitybased facilities. A call for such education arises from this field test of the Cougar 1.0.

Healthy People 2010 (HP 2010) is a nationwide effort which aims to improve public health and develop a comprehensive health care system for all Americans (Kyler \& Merryman, 2000). The Cougar 1.0 may be useful toward the accomplishment of the first goal of HP 2010: to increase healthy life in quantity and years. By using the Cougar 1.0 as a screening tool by occupational therapists or others, older persons may be able to lead longer, safer, and healthier lives in the comfort of their own homes.

This field-test showed the Cougar 1.0 is a reliable and valid tool for assessing home safety. The findings of this study conclude that there are indeed safety hazards that need to be addressed and remedied. The average per patient cost of medical expenses related to falls in 1994 was $\$ 12,392$ (Tinetti et al., 1994). This amount is much greater than the cost of an environmental assessment with a tool such as the Cougar 1.0. Per patient fall medical costs are also far greater than the low cost of many simple yet important environmental modifications. Many of the safety hazards identified in the Cougar 1.0 field test can be easily remedied by simples measures such as posting telephone numbers by the phone, obtaining fire extinguishers, installing grab bars, and obtaining throw rugs and bath mats without non-slip backing. Occupational therapists can utilize the Cougar 1.0 to address environmental hazards and educate older persons on 
suggestions to increase safety in their home

environment easily and cost-effectively.

\section{References}

American Association of Retired Persons (AARP). (2002). Falls among older persons and the role of the home: An analysis of cost, incidence, and potential savings from home modification. Retrieved January 23, 2004, from http://research.aarp.org/il/ib56_falls.html

American Occupational Therapy Association. (n.d.) AOTA's Specialist Directory. Retrieved February 21, 2005, from http://www.aota.org/featured/area6/links/FindAnOT1.asp?S=1

Bailey, D. (1997). Research for the health professional- a practical guide (2nd ed.). Philadelphia: F. A. Davis.

Beghe, C. (2004). Review: Interventions targeting intrinsic and environmental risk factors reduce falls in older person. American College of Physicians Journal Club, 141(1), 17.

Brandeis University. (2003). Injuries to the elderly cost more than $\$ 8$ billion annually. Retrieved January 26, 2004, from http://my.brandeis.edu/news/item?news\%5fitem\%5fid=101125\&show\%5frelease\%5fdate=1

Cannava, E. (1994). Gerodesign: Safe and comfortable living spaces for older adults. Geriatrics, 49(11), 45-49.

Carter, S. E., Campbell, E. M., Sanson-Fisher, R. W., Redman, S., \& Gillespie, W. J. (1997). Environmental hazards in the homes of older people. Age and Aging, 26, 195-202.

Clemson, L., Roland, M., \& Cumming, R.G. (1997). Types of hazards in the homes of elderly people. The Occupational Therapy Journal of Research, 17(3), 200-213.

Clemson, L., Cumming, R. G., \& Heard, R. (2003). The development of an assessment to evaluate behavioral factors associated with falling. American Journal of Occupational Therapy, 57(4), 380-388.

Close, J., Ellis, M., Hooper, R., Glucksman, E., Jackson, S., Swift, C. (1999). Prevention of falls in the elderly trial (PROFET): A randomized controlled trial. The Lancet (353), 93-97.

Comprehensive Rehabilitation and Mental Health Services. (2003). SAFER tool. Retrieved October 29, 2003, from http://www.cotarehab.ca/index.cfm?fuseaction=Products

Consumer Product Safety Commission. (n.d.). Safety for older consumers home safety checklist. Retrieved November 23, 2003, from http://www.cpsc.gov/CPSCPUB/PUBS/701.html

Coolbaugh, K., \& Rhodes, C., \& Bryan, N. (2004). The cougar home safety assessment for older persons version 1.0. Retrieved May 2, 2005, from http://www.misericordia.edu/images/ot/Version\%201.0.pdf

Cumming, R. G., Thomas, M., Szonyi, G., Frampton, G., Salkeld, G., \& Clemson, L. (2001). Adherence to occupational therapist recommendations for home modifications for falls prevention. American Journal of Occupational Therapy, 55, 641-648.

DePoy, E., and Gitlin, L. (2005). Introduction to research- Understanding and applying multiple strategies (3rd ed.). St. Louis: Elsevier/Mosby.

Fleming, D. W. (2002). Falls among older Americans: CDC prevention efforts before the senate subcommittee on aging, committee on health, education, labor and pensions. Retrieved January 18, 2004, from http://www.hhs.gov/asl/testify/t020611.html

Gill, T., William, C. S., Robison, J. T., \& Tinetti, M. E. (1999). A population-based study of environmental hazards in the homes of older persons. American Journal of Public Health, 89, 553.

Hotchkiss, A., Fisher, A., Robertson, R., Ruttencutter, A., Schuffert, J., \& Barker, D. B. (2004). Convergent and predictive validity of three scales related to falls in the elderly. American Journal of Occupational Therapy, 58(1), 100-103.

Jensen, J., Lundin-Olsson, L., Nyberg, L., \& Gustafson, Y. (2002). Fall and injury prevention in older people living in residential care facilities: A cluster-randomized trial. Annals of Internal Medicine, 146, 733-741. 
Klein, K., and Ritzel, D. (2001). Falls pose a serious threat to the elderly. Retrieved January 24, 2005, from http://www.nsc.org/issues/ifalls/falthreat.htm

Kyler, P., \& Merryman, M. B. (2000, November 6). Healthy people 2010. OT Practice, CE-1-CE-7.

Letts, L., Baum, C., \& Perlmutter, M. (2003). Person-environment-occupation assessment with older adults. OT Practice, 8(10), 27-34.

Lombard, M., Snyder-Duch, J., and Bracken, C. (2004). Practical resources for assessing and reporting intercoder reliability in content analysis research projects. Retrieved January 21, 2005, from http://www.temple.edu/mmc/reliability

Lysack, C. L., MacNeill, S. E., \& Lichtenberg, P. A. (2001). The functional performance of elderly urban African American women who return home to live alone after medical rehabilitation. American Journal of Occupational Therapy, 55, 433-440.

Lysack, C. L., \& Neufeld, S. (2003). Occupational therapist home evaluations: Inequalities, but doing the best we can? American Journal of Occupational Therapy, 57, 369-379.

Microsoft Office Online. (n.d.). Excel. Retrieved February 21, 2005, from http://office.microsoft.com/enus/FX010858001033.aspX

Miller, P. A. (2003). Home safety: The expanding role of OT.OT Practice, 8(1), 10-14.

National Center for Injury Prevention and Control. (n.d., a). 10 leading causes of death, United States. Retrieved February 2, 2005, from http://webappa.cdc.gov/cgi-bin/broker.exe

National Center for Injury Prevention and Control. (n.d., b). Unintentional fall deaths and rates per 100,000. Retrieved February 2, 2005, from http://webappa.cdc.gov/cgi-bin/broker.exe

National Center for Injury Prevention and Control. (n.d., c). Unintentional fall nonfatal injuries and rates per 100,000. Retrieved February 2, 2005, from http://webappa.cdc.gov/cgi-bin/broker.exe

National Center for Injury Prevention and Control. (n.d., d). Unintentional residential fire/flame deaths and rates per 100,000. Retrieved February 2, 2005, from http://webappa.cdc.gov/cgibin/broker.exe

National Center for Injury Prevention and Control. (n.d., e). 2002, United States unintentional fall deaths and rates per 100,000. Retrieved February 2, 2005, from http://webappa.cdc.gov/cgibin/broker.exe

Portney, L. G., \& Watkins, M. P. (2000). Foundations of clinical research- applications to practice (2nd ed.). Upper Saddle River: Prentice Hall Health.

Russel, C., Fitzgerald, M. H., Williamson, P., Manor, D., \& Whybrow, S. (2002). Independence as a practical issue in occupational therapy: The safety clause. American Journal of Occupational Therapy, 56, 369-379.

Skymeg Software. (n.d.). PRAM: a program for reliability assessment with multiple coders. Retrieved February 15, 2005, from http://www.geocities.com/skymegsoftware/pram.html

Statistical Package for Social Sciences. (December 2001). SPSS base for windows (Version 11.0) [Computer software]. Chicago, IL: SPSS Inc.

Stemler, S. (2001). An overview of content analysis. Practical Assessment, Research \& Evaluation, 7(17). Retrieved January 24, 2005, from http://pareonline.net/getvn.asp?v=7\&n=17

Tanner, E. K. (2003). Assessing home safety in homebound older adults. Geriatric Nursing, 24(4), 250256.

Tinetti, M. E., Baker, D. I., McAvay, G., Claus, E. B., Garrett, P., Gottschalk, M., Koch, M. L., Trainor, K., \& Horwitz, R.I., 1994). (2004). A multifactorial intervention to reduce the risk of falling among elderly people living in the community. New England Journal of Medicine, 331, 821-827.

United States Census Bureau. (2001, October). The 65 years and over population: 2000. Retrieved February 2, 2005, from http://www.census.gov/prod/2001pubs/c2kbr01-10.pdf

United States Department of Health and Human Services. (2003). A profile of older Americans. Retrieved January 26, 2004 from http://www.aoa.gov/prof/statistics/profile/2003/2003profile.pdf

Weir, E., and Culmer, L. (2004). Fall prevention in the elderly population. Canadian Medical Association Journal, 171, 724. 
Wilkins, S., Jung, B., Wishart, L., Edwards, M., \& Norton, S. G. (2003). The effectiveness of communitybased occupational therapy education and functional training programs for older adults: A critical literature review. Canadian Journal of Occupational Therapy, 70, 214-225.

Woodland, J. E., \& Hobson, S. J. G. (2003). An occupational therapy perspective on fall prevention among community-dwelling older adults. Canadian Journal of Occupational Therapy, 70, 174181.

\section{Acknowledgements}

We would like to thank the participating residents for completing the field test, and Molly Mika, M.S., OTR/L, for her feedback during the writing of this paper. We would also like to acknowledge and thank the Consumer Product Safety Commission for providing a checklist which we adapted in the development of the Cougar 1.0.

\section{Author Notes}

At the time of this study, Kristen Coolbaugh, MS, OTR/L, and Christin Rhodes, MS, OTR/L, were graduate occupational therapy students in the five-year occupational therapy BS/MS program at College Misericordia. Kristin Coolbaugh is now an occupational therapist with Wyoming Valley Health Care in Wilkes-Barre, Pennsylvania. Christin Rhodes is now employed by the Cerebral Palsy Associations of New York State in New York City. Grace S. Fisher, Ed.D., OTR/L, was the faculty director of this project. She is an Assistant Professor of Occupational Therapy at College Misericordia in Dallas, Pennsylvania.

Interested parties are encouraged to download the Cougar Home Safety Assessment from the website stated within. Permission is granted for you to reproduce and use the assessment freely for educational and occupational therapy practice purposes. Requests to use the assessment for research purposes, or to adapt it, should be addressed to: gfisher@misericordia.edu.

Author Information

Grace S. Fisher, Ed.D., OTR/L

College Misericordia Occupational Therapy Department

301 Lake Street

Dallas, PA 18612

Ph.: 570-674-8051

Fax.: 570-674-3052

E-mail: gfisher@misericordia.edu

Kristen Coolbaugh, M.S., OTR/L

Christin Rhodes, M.S., OTR/L

College Misericordia Occupational Therapy Department

301 Lake Street

Dallas, PA 18612 


\section{Appendix A}

\section{Most Common Rating Given by Three Raters for 14 Residences}

\begin{tabular}{|c|c|c|c|c|}
\hline Criterion & Safe & Unsafe & $\begin{array}{c}\text { Not } \\
\text { Applicable }\end{array}$ & $\begin{array}{l}\text { No Agreement } \\
\text { between raters }\end{array}$ \\
\hline $\begin{array}{l}\text { There is at least one grab bar present and properly installed } \\
\text { beside the toilet. }\end{array}$ & $21 \%$ & $79 \%$ & & \\
\hline Emergency numbers are posted on or near the telephone. & $36 \%$ & $64 \%$ & & \\
\hline All small rugs and runners are slip-resistant. & $36 \%$ & $64 \%$ & & \\
\hline The attic, if used, is accessible. & $36 \%$ & & $64 \%$ & \\
\hline $\begin{array}{l}\text { There is a fire extinguisher on every level of the house or } \\
\text { apartment. }\end{array}$ & $43 \%$ & $57 \%$ & & \\
\hline $\begin{array}{l}\text { There is a step stool which is stable and in good condition } \\
\text { on every level of the residence. }\end{array}$ & $43 \%$ & $57 \%$ & & \\
\hline $\begin{array}{l}\text { Candles are located in a place away from flammable objects } \\
\text { such as curtains, bedding, or carpeting. }\end{array}$ & $50 \%$ & & $50 \%$ & \\
\hline $\begin{array}{l}\text { There is a carbon monoxide detector present and in working } \\
\text { order on every level. }\end{array}$ & $50 \%$ & $50 \%$ & & \\
\hline $\begin{array}{l}\text { Small appliances such as toasters, hairdryers, and shavers } \\
\text { are in good condition. }\end{array}$ & $57 \%$ & $43 \%$ & & \\
\hline $\begin{array}{l}\text { There is at least one grab bar present and properly installed } \\
\text { in the bathtub or shower. }\end{array}$ & $57 \%$ & $43 \%$ & & \\
\hline The garage is well lit. & $57 \%$ & & $43 \%$ & \\
\hline There is a nonskid mat outside the bathtub or shower area. & $64 \%$ & $36 \%$ & & \\
\hline Railings are present and sturdy. & $64 \%$ & $29 \%$ & $7 \%$ & \\
\hline Closets and storage areas are well lit. & $64 \%$ & $36 \%$ & & \\
\hline $\begin{array}{l}\text { Flashlights, especially by the bed, are present and } \\
\text { accessible. }\end{array}$ & $71 \%$ & $29 \%$ & & \\
\hline Exits, hallways, and passageways are kept clear. & $71 \%$ & $14 \%$ & & \\
\hline $\begin{array}{l}\text { There is a non-slip surface, a nonskid mat, or abrasive strips } \\
\text { in the bathtub or shower. }\end{array}$ & $79 \%$ & $21 \%$ & & \\
\hline \begin{tabular}{|l|} 
The covering on the stairs are firmly attached and in good \\
condition.
\end{tabular} & $79 \%$ & & $7 \%$ & $14 \%$ \\
\hline The stairs are free of clutter. & $79 \%$ & $14 \%$ & $7 \%$ & \\
\hline \begin{tabular}{|l} 
Portable heaters, ash trays, or other fire sources are located \\
away from bedding.
\end{tabular} & $86 \%$ & & $14 \%$ & \\
\hline Extension cords carry a proper load. & $86 \%$ & & $14 \%$ & \\
\hline Water temperature is 120 degrees or lower. & $86 \%$ & $14 \%$ & & \\
\hline $\begin{array}{l}\text { There is a smoke detector present and in working order on } \\
\text { every level. }\end{array}$ & $93 \%$ & $7 \%$ & & \\
\hline $\begin{array}{l}\text { There is an easily accessible telephone in every room in } \\
\text { case of a fall. }\end{array}$ & $93 \%$ & $7 \%$ & & \\
\hline All cords are placed out of the flow of traffic. & $93 \%$ & $7 \%$ & & \\
\hline Cords are out from beneath carpeting and furniture. & $93 \%$ & $7 \%$ & & \\
\hline
\end{tabular}




\begin{tabular}{|c|c|c|c|c|}
\hline Criterion & Safe & Unsafe & $\begin{array}{c}\text { Not } \\
\text { Applicable }\end{array}$ & $\begin{array}{l}\text { No Agreement } \\
\text { between raters }\end{array}$ \\
\hline Carpeting is firmly attached and in good condition. & $93 \%$ & & & $7 \%$ \\
\hline Night lights are present and in working order. & $93 \%$ & $7 \%$ & & \\
\hline The exhaust system for the stove works properly. & $93 \%$ & $7 \%$ & & \\
\hline $\begin{array}{l}\text { Commonly used items are stored in locations that can be } \\
\text { easily and safely reached. }\end{array}$ & $93 \%$ & $7 \%$ & & \\
\hline The toilet height allows for safe transferring. & $93 \%$ & $7 \%$ & & \\
\hline Steps are not excessively slippery and in good condition. & $93 \%$ & & $7 \%$ & \\
\hline Steps are even and of the same size and height. & $93 \%$ & & $7 \%$ & \\
\hline There is adequate lighting. & $93 \%$ & & $7 \%$ & \\
\hline $\begin{array}{l}\text { Furnishings and flammable objects such as curtains or rugs } \\
\text { are located away from heaters. }\end{array}$ & $100 \%$ & & & \\
\hline $\begin{array}{l}\text { The height of chairs, couches, and beds are appropriate for } \\
\text { safe transfers. }\end{array}$ & $100 \%$ & & & \\
\hline $\begin{array}{l}\text { Large appliances such as laundry machines and refrigerators } \\
\text { are accessible and in good condition. }\end{array}$ & $100 \%$ & & & \\
\hline $\begin{array}{l}\text { All outlets and switches are covered so that there is no } \\
\text { exposed wiring. }\end{array}$ & $100 \%$ & & & \\
\hline $\begin{array}{l}\text { Cords are not attached to walls or baseboards with nails or } \\
\text { staples. }\end{array}$ & $100 \%$ & & & \\
\hline Cords are in good condition (not frayed or cracked). & $100 \%$ & & & \\
\hline $\begin{array}{l}\text { Floor surfaces are not excessively slippery or in poor } \\
\text { condition. }\end{array}$ & $100 \%$ & & & \\
\hline $\begin{array}{l}\text { The person does not have to walk through a dark area to } \\
\text { reach a light switch. }\end{array}$ & $100 \%$ & & & \\
\hline $\begin{array}{l}\text { Hallways, passageways between rooms, and other heavy } \\
\text { traffic areas are well lit. }\end{array}$ & $100 \%$ & & & \\
\hline $\begin{array}{l}\text { Flammable objects such as towels or curtains are located } \\
\text { away from the stove. }\end{array}$ & $100 \%$ & & & \\
\hline $\begin{array}{l}\text { There is no excessive grease or clutter on or around the } \\
\text { stove. }\end{array}$ & $100 \%$ & & & \\
\hline It is safe to reach for dials on the stove. & $100 \%$ & & & \\
\hline Commonly used items can be easily reached. & $100 \%$ & & & \\
\hline $\begin{array}{l}\text { There is adequate lighting in work areas in the house or } \\
\text { apartment. }\end{array}$ & $100 \%$ & & & \\
\hline All chemical products are properly stored. & $100 \%$ & & & \\
\hline $\begin{array}{l}\text { The parking area and the entrance to the house or apartment } \\
\text { are well lit. }\end{array}$ & $100 \%$ & & & \\
\hline The parking area and the entrance are easily accessible. & $100 \%$ & & & \\
\hline $\begin{array}{l}\text { Walkways and stairs leading to the entrance are clear and in } \\
\text { good condition. }\end{array}$ & $100 \%$ & & & \\
\hline $\begin{array}{l}\text { Walkways leading to the mailbox are clear and in good } \\
\text { condition. }\end{array}$ & $100 \%$ & & & \\
\hline Garbage is kept in an accessible place and disposed of & $100 \%$ & & & \\
\hline
\end{tabular}




\begin{tabular}{|l|l|l|l|l|}
\hline \multicolumn{1}{|c|}{ Criterion } & Safe & Unsafe & $\begin{array}{c}\text { Not } \\
\text { Applicable }\end{array}$ & $\begin{array}{c}\text { No Agreement } \\
\text { between raters }\end{array}$ \\
\hline regularly. & & & & \\
\hline $\begin{array}{l}\text { The distance from the elevator to the apartment is } \\
\text { manageable. }\end{array}$ & & & $100 \%$ & \\
\hline The buttons in the elevator are accessible. & & & $100 \%$ & \\
\hline
\end{tabular}

